\title{
Who are we?
}

\section{Efforts to catalogue and understand the human microbiome are opening up a whole new research frontier. But the earlier Human Genome Project should provide a cautionary lesson about overselling.}

/ $/ 1 /$ ho am I?" is a question that is often asked and seldom answered. But as several articles in this issue suggest, the question itself may need to be reframed: biologists are discovering that it is frequently more informative to ask, "Who are we?"

The 'we' refers to the wild profusion of bacteria, fungi and viruses that colonize the human body. These unseen passengers number in the trillions. According to one common estimate, the human gut contains at least a kilogram of bacteria alone. They contribute so much to human biology that it is difficult to say where the body ends and the microbes begin - which is why several massive projects have now started up to characterize the human microbiota in its entirety (see page 578).

Microbiologists are understandably excited by this opportunity. So, too, are the food and pharmaceutical industries. When it comes to profitable applications to human health, the microbiome could well offer distinct advantages over the more famous genome. Human genes are notoriously difficult and risky to tamper with. But, in theory at least, the microbiome should be relatively easy to change by the selective addition or removal of bacterial species, or by altering their genetic components. This idea has some basis. Antibiotics and 'probiotic' foods have already been shown to calm inflammatory bowel diseases in some instances. In this issue, for example, researchers show how intestinal inflammation can be reduced by a single molecule produced by a gut bacterium (see pages 602 and 620). And there is increasing acceptance that certain foods, or the bacteria contained in them, can alter gut microbiota in ways that are beneficial to health in general.

The new appreciation of the microbiome comes just as some observers have started to question whether the human genome can deliver on its once-hyped promises to tackle disease. To take just one example, anyone so inclined can now pay genetic-testing companies for a preliminary rundown of the genetic variations associated with his or her risk of developing cancer, obesity and other conditions. But the risks identified are often so low or unclear that people are questioning whether the information will actually prompt the changes in health behaviour, such as losing weight, that could make them valuable (see page 570).

For all the excitement, however, researchers involved in the human microbiome efforts can learn a valuable lesson from the genome experience. Simply put: be circumspect. Don't oversell the human microbiome until its medical promise has been established. Remember that the understanding of these microbial communities is still fragmentary, at best - and that it is far from established that the microbiota can be radically altered without upsetting the balance and causing harm, or that any alterations will last more than a few months. Indeed, attempts to understand the dynamics of gut colonization are still in their infancy (see page 581).

In the meantime, microbiologists
"Don't oversell the human microbiome until its medical promise has been established." should celebrate their quest to map, catalogue and understand the human microbiome for the inspiring saga it is. Certainly there is food for thought in the fact that everyone has inside them exotic environments that support communities as diverse as any rainforest. There is a unique ecological perspective on food itself, and the effects that different foodstuffs, such as processed versus unprocessed ones, have on these environments.

There is a compelling new take on humankind's place in the world - a realization that "Who am I?" cannot be fully answered until it is fully understood who 'we' are.

\section{Animal tests inescapable}

\section{The ambitious scope of Europe's chemicals legislation demands some innovative toxicology.}

T he European Union's (EU) Registration, Evaluation, Authorisation and Restriction of Chemicals (REACH) directive, which took effect a year ago, on 1 June 2007, is widely regarded as the strictest chemical safety law in the world. Unlike the 1981 EU legislation it replaces, or the US Toxic Substances Control Act, REACH applies to all existing chemicals, not just new ones .

If nothing else, that requirement is likely to cause six months of immense stress at the organization created to administer REACH, the European Chemicals Agency in Helsinki. The agency will open its doors to registration on 1 June this week. And with every chemical manufacturer or importer in Europe facing a 1 December deadline to do the initial registration on every compound it had put on the market before 1981, agency staffers are braced for an estimated 180,000 applications.

More importantly, however, the requirement to test all those old chemicals has made REACH a case study in difficult choices. In following one policy - ensuring the safety of its citizens - the European Union may have severely strained another: lessening the use of animals in regulatory toxicology, and in research in general. Working through that backlog without sacrificing a lot of animals will be impossible.

Happily, the actual number of sacrifices is likely be less dramatic than it might have been. Partly this is because safety data are already thought to exist on many of the older chemicals (although no one has comprehensive statistics). And partly it is because of REACH itself. In 2002, while the directive was still being drafted, the European Union expanded and accelerated work at the European Centre for 